\title{
Groundwater Level Analyse In Urgench City With Using Modflow Modeling And Forecasting System
}

\author{
Aybek Arifjanov ${ }^{1 *}$, Luqmon Samiev ${ }^{1}$, Shodiyor Yusupov ${ }^{1}$, Djamila Khusanova ${ }^{1}$, Zokhidjon \\ Abdulkhaev ${ }^{2}$ and Suhrob Tadjiboyev ${ }^{3}$ \\ ${ }^{1}$ Tashkent Institute of Irrigation and Agricultural Mechanization Engineers, Tashkent, Republic of \\ Uzbekistan \\ ${ }^{2}$ Fergana Polytechnic Institute. Fergana - Republic of Uzbekistan \\ ${ }^{3}$ Karshi Engineering Economic Institut. Karshi - Republic of Uzbekistan
}

\begin{abstract}
The study was conducted as part of a project to develop an automation system for monitoring groundwater in the city of Urgench. The possibilities of modeling and forecasting modeling MODFLOW in groundwater were studied. According to the results, regularities of the level and behavior of groundwater in the city of Urgench were revealed. According to the survey, the direction of movement of groundwater in the city of Urgench shifts in a northwesterly direction to a slope of 0.0008 . According to the geophilized model, its high-traffic zone is located at a depth of 10-15 m, from 4-5 m per second.
\end{abstract}

\section{Introduction}

In the next hundred years of human development, cities have been decided not only as a set of buildings where people live and work, but also as complex structures, smart technologies, unique geotextiles. Global problem of the sphere is improving the efficiency of complex reclamation systems of cities through monitoring, modeling of real conditions, the optimal layout and regime of groundwater in this geotextile, the types of its formation and these elements. According to the United Nations, in "International Christian Partnership", report on urban development, said that nearly $80 \%$ of the world's major cities would be affected by the level of corrosion of groundwater engineering communications in the future, $16 \%$ of which would be flooded by global climate change.

\section{Problem statement}

Among the main problems in the cities of our country is the proximity of groundwater to the surface, which leads to problems in the operation of engineering communications. In particular, according to a study conducted in Urgench [1,2,3,4], the state of groundwater has negatively affected $60 \%$ of existing buildings and structures. Although reclamation

\footnotetext{
*Corresponding author: a.arifjanov@tiiame.uz
} 
monitoring has been established in the region, the lack of modern technology in analyzing the results and drawing conclusions makes it difficult to draw conclusions about the real situation and develop measures.

On the basis of the Resolution of the President of the Republic of Uzbekistan dated December 6, 2012 No PP 1874 "On measures to implement the master plan of Urgench", Cabinet of Ministers developed and approved a comprehensive action plan. On the basis of these measures, Research Institute for Groundwater Level Reduction in Urgench "UZGASHKLITI" implemented a project "Creation of an automated groundwater monitoring system in Urgench." In this project created an innovative monitoring system and expanded the application of groundwater modeling principles.

\section{Solution method}

One of the main problems in recent days is to improve the system of groundwater modeling and conclusions based on these principles. The study describes the application of the MODFLOW modeling system for this purpose, application of the method of spatial modeling of groundwater levels in real conditions in the implementation of tasks developed under the project $[5,6,7,8]$.

\section{Object of research}

The city of Urgench is the administrative center of Khorezm region, located between the northern latitudes $41^{\circ} 31^{\prime} 30^{\prime \prime}$ and $412034^{\prime} 20^{\prime \prime}, 60^{\prime \prime} 34^{\prime} 11^{\prime \prime}$ and $60^{\circ} 41^{\prime} 22$ " east, the city and its suburbs. The distance from Urgentch to the capital is $1119 \mathrm{~km}$. The climate is sharply continental, with an absolute maximum of $45.1^{\circ} \mathrm{C}$ in hot summers and an absolute minimum of $-28.4^{\circ} \mathrm{C}$ in cold winters, with an average annual temperature of $12.4^{\circ} \mathrm{C}$. With the increase in temperature, the average perennial index rose to $13.1^{\circ} \mathrm{C}$, the amount of precipitation is $104 \mathrm{~mm}$ per year.

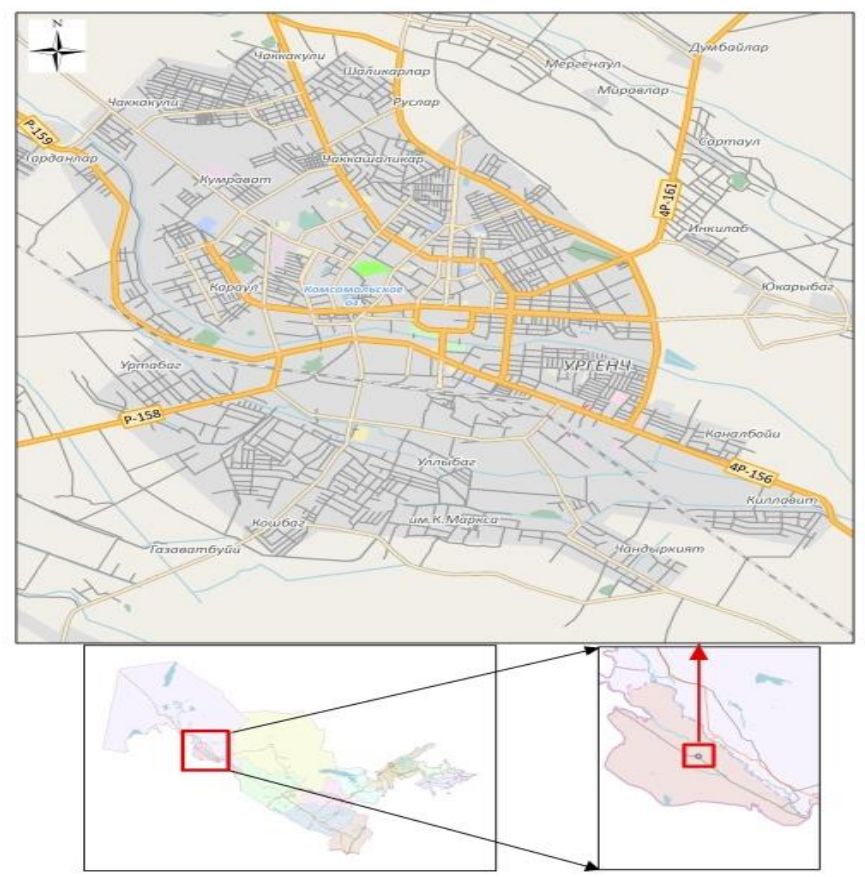

Fig. 1. Location of the research object 
The study area is $100 \mathrm{~km} 2$ and the relief is flat $96-103 \mathrm{~m}$ above sea level. The region is covered by groundwater monitoring with an automated information monitoring system using the principles of modern geoinformation technologies.

\section{Methods and materials}

MODFLOW (Flow Modeling) was developed in the 1970s using the American FARTRON programming language and has created generations that have evolved to the present day. The MODFLOW modeling and forecasting system is developed by several companies and is not interconnected $[9,10,11,12]$. In our study, Visual Modflow Flex 2015 was used. The modeling capabilities of the program are well covered in the following study.

The modeling system begins with the formation of task-related data (Figure 2). The program works accurately only when the data is entered in full. Therefore, the existing hydrogeological conditions require the development of a comprehensive database in the form of geographical information $[13,14,15,16]$.

\section{Analysis step}

The area's Relief model was created using the ALOS Global Digital Surface Model. The base of lithology, filtration coefficient, soil porosity and water retention properties was formed from the data of geological reports of the regional geofund of UZGASHKLITI (Figure 1). Border conditions were formed as a result of satellite imagery and data from the Khorezm Melioration expedition and direct field research:

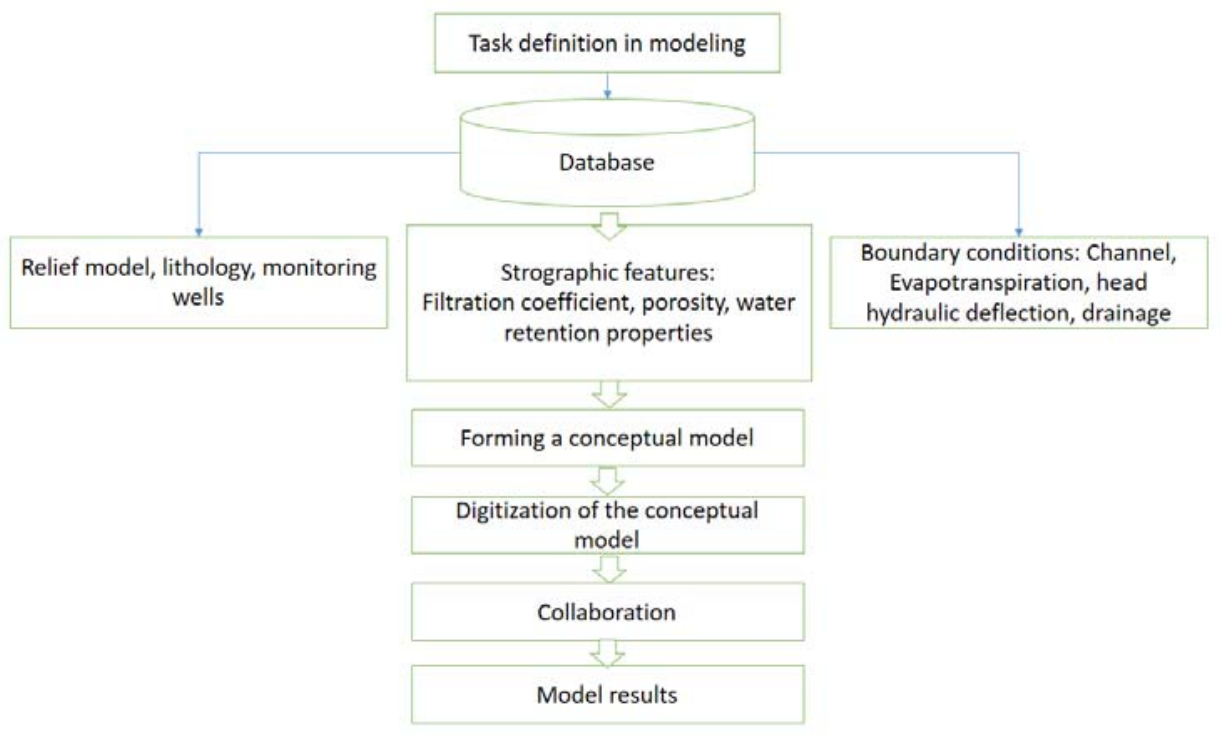

Fig. 2. Task definition in modeling

The conceptual model was developed by bringing the data into a spatial view. The calibration of the developed conceptual model was compared with the data obtained as a result of field research.

Data from 66 automated monitoring wells in Urgench were used to calibrate groundwater levels. 


\section{Conclusions and discussions}

The relief of Urgench is flat, which ensures the slow movement of groundwater. The flow direction is from southeast to northwest (Fig. 3). Lithologically, the soil close to the surface is covered with loamy soils and sands. This reduces the filtration in some places to a layer thickness of $0.5-2 \mathrm{~m}$. The next layer consists of sand of different fractional structure. Its filtration coefficient ranges from 0.5 to $5 \mathrm{~m} /$ day. According to the results of the geofiltration model (Fig. 4b), the movement of real groundwater was twice as strong as at the surface at a depth of $10 \mathrm{~m}$ above the ground. In this stronger flow region, the direction is slightly northward $[17,18,19,20]$.

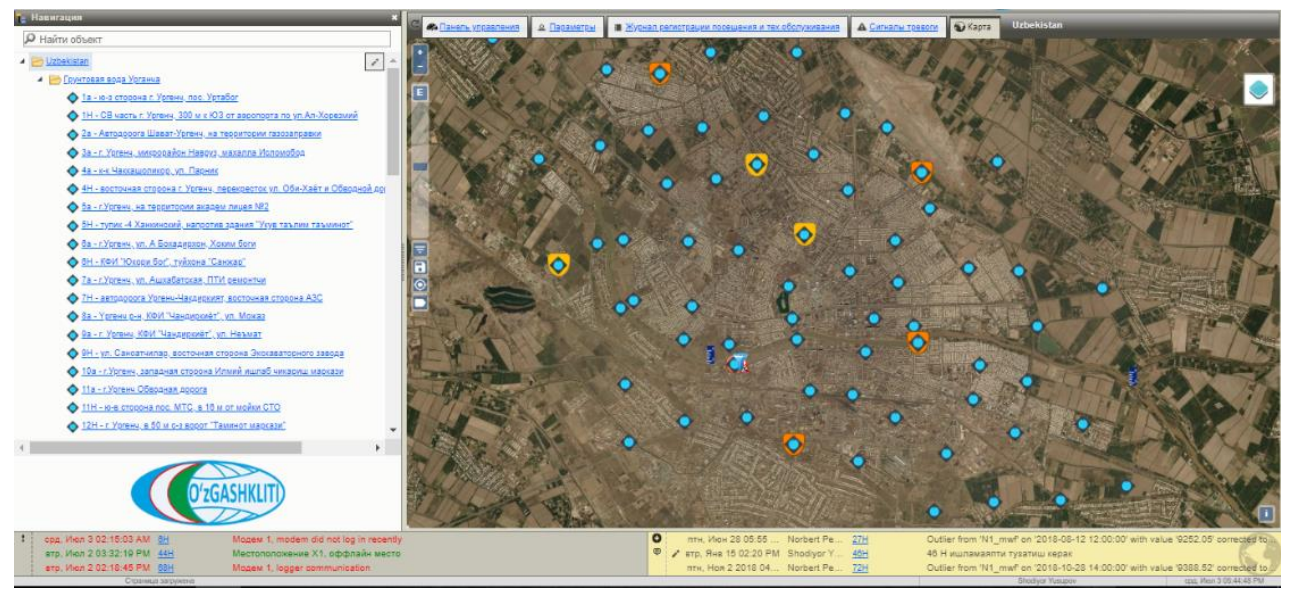

Fig. 3. Interface of the automated groundwater monitoring system of Urgench city
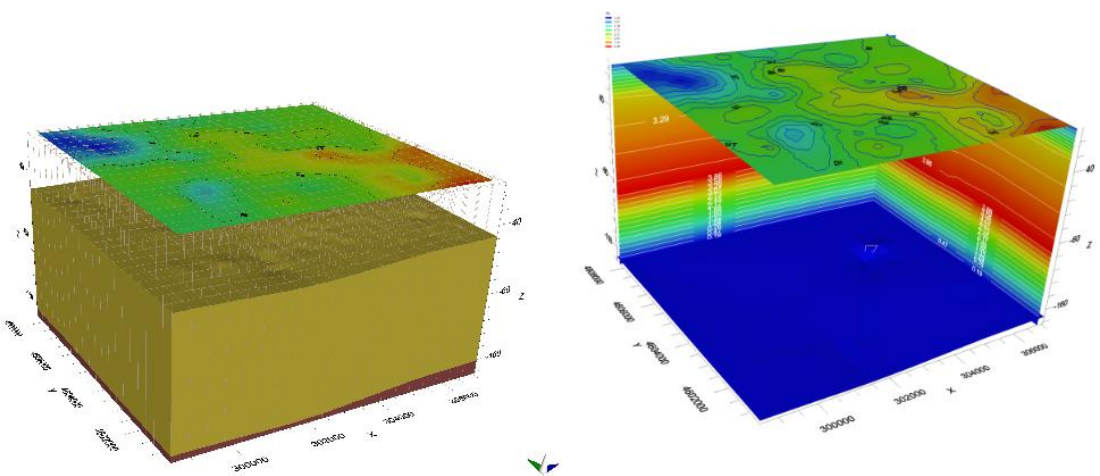

Fig. 4. The result of the modeling is a) Strographic structure of the area and high groundwater horizon $\mathrm{m}$.; b) geofiltration model in cross section ( $\mathrm{m} 3$ / day).

In the conceptual modeling, the boundary conditions of the groundwater of the region were developed in digital form. Based on the results of the model, the hydraulic gradient of the area was modeled, the hydraulic gradient model calculated in three dimensions showed that the groundwater movement was directed to the northwest (Figure 5). The pressure level of the modeled groundwater horizon ranged from $99 \mathrm{~m}$ to $94.5 \mathrm{~m}$, with a bed of 0.0008 . Under such conditions, groundwater is practically runoff. The uniformity of the water level and gradient models means that there are no anomalous barriers in the area. 


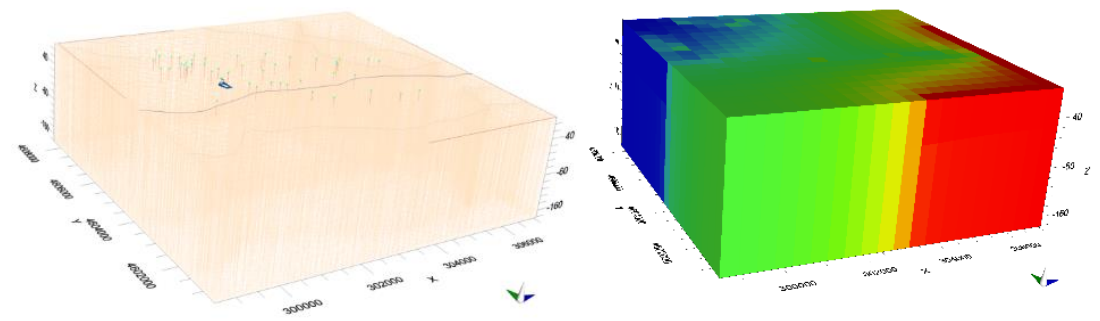

Fig. 5. Results of conceptual modeling a) Numerical representation of boundary conditions; b) Block diagram of the hydraulic gradient.

According to the results of the conceptual model of groundwater boundary conditions, the share of groundwater flowing from the environment in the budget of the groundwater balance in the region is large. Approximately $40 \%$ of this amount of incoming water leaves unchanged. Drainage networks make a very small contribution to the balance of groundwater. The Shovat canal plays an important role in lowering the groundwater level of the region. A large part of the mass of groundwater entering from above serves as a canal drain. The role of evaporation and precipitation in the dynamics of groundwater is very noticeable (Figure 6).

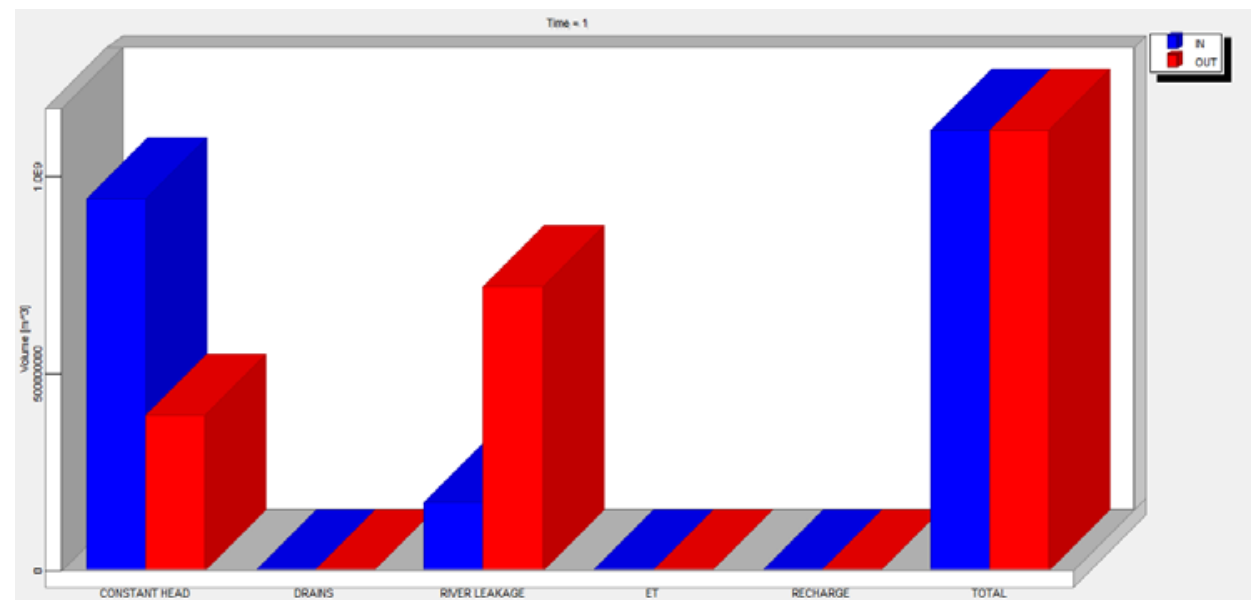

Fig. 6. Groundwater balance "Budget" formation (income in blue, expenditure in red)

In determining the reliability of the modeling results, the ratio of the model results to the measurement results was studied. The results showed that the model worked $65 \%$ correctly. The straight-line correlation was 0.57 (Figure 7). 

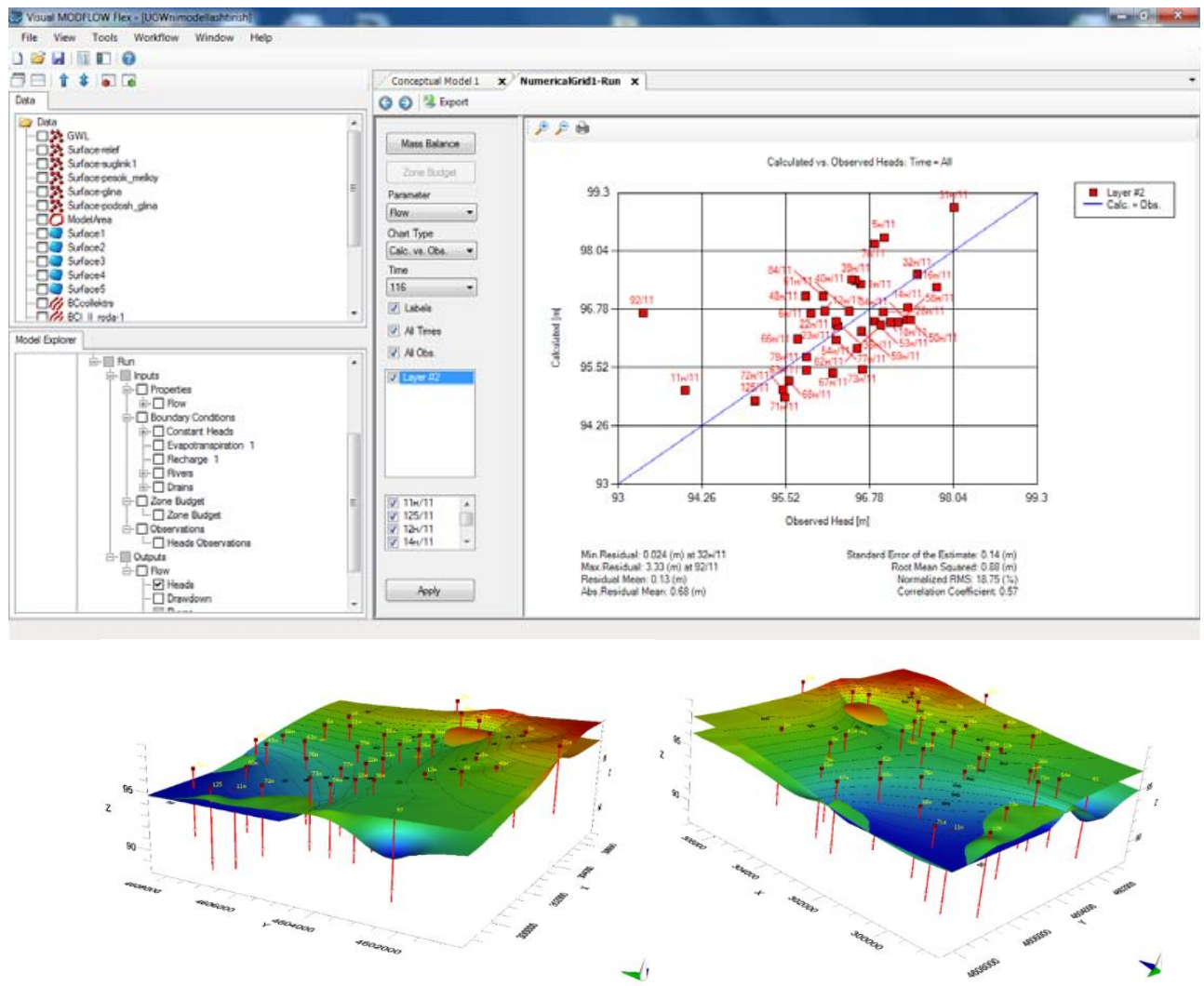

Fig. 7. Calculation of model reliability a) statistical reliability test; b) three-dimensional view of the modeled and measured groundwater level

A three-dimensional comparison of the modeled and measured data showed that (Fig. 7 b) the modeling gives more accurate results than the interpolation. The modeling results were more accurately compared to the measured data bed. In summary, the modeling yielded high-precision results when some dimensional calculations were performed. Conclusion. The development of a modeling system is important in drawing conclusions based on the specific conditions of groundwater. The MODFLOW modeling system is a non-choice software in studying the performance efficiency of a reclamation system. Its capabilities give high results in the study of groundwater regime accuracy. This requires the correct selection and input of data subjectively. It was found that the results obtained in the example of the city of Urgench give more accurate results than the results of spatial interpolation on the groundwater level, even when the model operates with an accuracy of $65 \%$.

\section{References}

1. Alsubaie, N.M. (2012). The Potential of Using Worldview-2 Imagery for Shallow Water Depth Mapping. Université de Calgary. Alberta, 85p

2. Awan, Usman Khalid. "Coupling Hydrological and Irrigation Schedule Models for the Management of Surface and Groundwater Resources in Khorezm, Uzbekistan." Accessed June 2017. $105 \mathrm{p}$. 
3. Blaschke T. Object Based Image Analysis for Remote Sensing. ISPRS Journal of Photogrammetry and Remote Sensing, 65 (1) Pp. 2-16A. Mecke, I. Lee, J.R. Baker jr., M.M. Banaszak Holl, B.G. Orr, Eur. Phys. J. E 14, 7 (2004)

4. Arifjanov, A., Fatxullaev, A. Natural Studies for Forming Stable Channel Sections (2020) Journal of Physics: Conference Series, 1425 (1). DOI: 10.1088/1742-6596/1425/1/012025

5. Arifjanov, A., Rakhimov, Q., Samiev, L., Abduraimova, D., Apakhodjaeva, T. Hydraulic friction coefficient at hydraulic mixing movement in pressure pipelines (2020) Journal of Advanced Research in Dynamical and Control Systems, 12 (7 Special Issue), pp. 1332-1336. DOI: 10.5373/JARDCS/V12SP7/20202233

6. Arifjanov, A., Juraev, S., Samiev, L., Ibragimova, Z., Babajanov, F. Determination of filtration strength and initial filtration gradient in soil constructions. (2020) Journal of Advanced Research in Dynamical and Control Systems, 12 (4 Special Issue), pp. 1860-1864. DOI: 10.5373/JARDCS/V12SP4/20201672

7. Arifzhanov, A.M. Method for calculation of the distribution of drift particles in variable section beds (VSB) (2004) Gidrotekhnicheskoe Stroitel'stvo, (2), pp. 44-45.

8. Arifzhanov, A.M. Distribution of Suspended Sediment Particles in a Steady-State Flow. (2001) Water Resources, 28 (2), pp. 164-166. DOI: 10.1023/A:1010375500148

9. Samiyev, L., Allayorov, D., Atakulov, D., Babajanov, F. The influence of sedimentation reservoir on hydraulic parameters of irrigation channels (2020) IOP Conference Series: Materials Science and Engineering, 883 (1), DOI: 10.1088/1757-899X/883/1/012031

10. Fatxulloyev, A., Abduraimova, D., Otakhonov, M., Atakulov, D., Samiev, L. Method designing of open drainages (2020) IOP Conference Series: Materials Science and Engineering, 883 (1),.DOI: $10.1088 / 1757-899 X / 883 / 1 / 012047$

11. Atakulov, D., Babajanov, F. Evaluation of the hydraulic and morfometric connections of the riverbed with using GIS(2020) IOP Conference Series: Materials Science and Engineering, 869 (4), DOI: $10.1088 / 1757-899 \mathrm{X} / 869 / 4 / 042028$

12. Abduraimova, D., Atakulov, D., Ibragimova, Z., Apakhodjaeva, T. Evaluation of erosion and accumulative process with using Geoinformation systems in water resource management (2019) International Conference on Information Science and Communications Technologies: Applications, Trends and Opportunities, ICISCT 2019. DOI: 10.1109/ICISCT47635.2019.9012020

13. Fatxulloyev, A., Allayorov, D., Otakhonov, M.Study of hydraulic parameters for concreting channels(2020) IOP Conference Series: Earth and Environmental Science, 614 (1).DOI: $10.1088 / 1755-1315 / 614 / 1 / 012054$

14. Fatxulloyev, A., Gafarova, A., Otakhonov, M., Allayorov, D. The hydraulic efficiency of the soil channels (2020) IOP Conference Series: Materials Science and Engineering, 883 (1). DOI: $10.1088 / 1757-899 X / 883 / 1 / 012042$

15. Rakhimov, K., Ahmedkhodjaeva, Xoshimov, S. Theoretical bases of hydraulic mixture in round cylindrical pipelines (2020) IOP Conference Series: Earth and Environmental Science, 614 (1). DOI: $10.1088 / 1755-1315 / 614 / 1 / 012095$

16. Samiyev, L., Allayorov, D., Atakulov, D., Babajanov, F. The influence of sedimentation reservoir on hydraulic parameters of irrigation channels (2020) IOP Conference Series: Materials Science and Engineering, 883 (1). DOI: 10.1088/1757-899X/883/1/012031

17. Fatxulloyev, A., Abduraimova, D., Otakhonov, M., Atakulov, D., Samiev, L. Method designing of open drainages (2020) IOP Conference Series: Materials Science and Engineering, 883 (1). DOI: $10.1088 / 1757-899 \mathrm{X} / 883 / 1 / 012047$

18. Fatxulloyev, A., Gafarova, A., Otakhonov, M., Allayorov, D. The hydraulic efficiency of the soil channels. IOP Conference Series: Materials Science and Engineering, 2020, 883(1), 012042 doi:10.1088/1757-899X/883/1/012042 
19. Arifjanov, A., Rakhimov, K., Abduraimova, D., Babaev, A., Melikuziyev, S. Hydrotransport of river sediments in hydroelelators. (2020) IOP Conference Series: Materials Science and Engineering, 869 (7). DOI: 10.1088/1757-899X/869/7/072003

20. Kenjabaev, S., Arifjanov, A., Frede, H., Apakhodjaeva, T. Ecohydrology of the Syrdarya River under irrigation water management in the Fergana Valley (2020) IOP Conference Series: Materials Science and Engineering, 883 (1). DOI: 10.1088/1757-899X/883/1/012081 